\title{
La polisemia de las palabras
}

\author{
Renato Ortiz \\ (Universidad de São Paulo, Campinas)
}

Recibido: 31/8/2011

Aprobado: 15/10/2011

\begin{abstract}
Resumen: El artículo examina las particularidades que tienen las significaciones y resignificaciones que el hombre, y el lenguaje en particular, da a términos como "universal", "cultura", "lenguaje". Este análisis se realiza desde la perspectiva de distintos campos: lingüístico, filosófico, sociológico, antropológico, y hasta religioso. Se presenta la dicotomía existente entre lo local y lo global, lo universal y lo particular, igualdades y diferencias. El texto alude a las distintas visiones que tienen las diversas religiones pero que a su vez, en estos tiempos de la globalización, pretenden retomar con fuerza la idea de la universalidad de la naturaleza del hombre.
\end{abstract}

Palabras clave: Cultura / lenguaje / lengua / estudios culturales / modernidad / sociología del conocimiento / globalización / religión

\section{Polysemy of Words}

Summary: The article presents the particularities of the definitions and redefinitions that man, and language in particular, gives to terms like "universal", "culture", "language". This analysis is performed from the perspective of different fields such as linguistics, philosophy, sociology, anthropology and even from religion. We present the dichotomy between local and global, universal and particular, similarities and differences. The text presents the different views that the world's religions have, but at the same time, which in this age of globalization are attempting to become unified in the concept of the universality of human nature.

Keywords: Culture / language / language / cultural studies / currency / sociology of knowledge / globalization / religion. 


\section{Naturaleza universal del hombre}

$\mathrm{E}$ 1 término 'universal' es polisémico, el uso que de este hacemos es generalmente dudoso e impreciso. Frente a sus múltiples sentidos, una estrategia posible para entenderlo es delinear mejor el concepto separándolo de los significados engañosos que lo aprisionan. ${ }^{1}$ El pensamiento actúa como herramienta de esclarecimiento, precisando los contornos de su validez teórica. Sin embargo, se puede contemplar otra alternativa. En este caso, no es tanto la definición más apropiada lo que interesa, sino en qué medida el término 'universal' nos remite a diferentes tradiciones intelectuales. Una primera acepción del concepto se vincula a la herencia del Iluminismo, que lo define como una cualidad de la "naturaleza humana". Sin embargo, los pensadores de los siglos XVII y XVIII diferían respecto de varias cuestiones, por ejemplo: el paso del estado salvaje a la vida colectiva, las formas de gobierno de los pueblos (democracia, despotismo, monarquía), la jerarquía de las razas, el origen del lenguaje. Pero en lo que sí coinciden todos es en que parten de un mismo principio: el hombre (Foucault cree que él integra uno de los pilares de la episteme moderna). Este es un ser objetivamente dado, raíz de la vida en sociedad, independientemente de la forma como ella se autogobierna o se estructura.

Jean-Jacques Rousseau, en la primera parte de su texto Discurso sobre el origen y los fundamentos de la desigualdad entre los hombres, describe las adversidades de este hombre solo, ocioso, rodeado de peligros y a la vez fuerte, ágil, capaz de resistir a las enfermedades, desde la infancia habituado a la intemperie:

No es una gran desgracia para su conservación la desnudez, la falta de vivienda y la privación de todas esas inutilidades que nosotros creemos tan necesarias. Si no tienen la piel velluda, no tienen ninguna necesidad de ella en los países cálidos y aprendieron rápido, en los países fríos, a apropiarse de las pieles de los animales que ellos vencieron (Rousseau 1996: 86).

El conde de Buffon (Georges Louis Leclerc) tiene una visión distinta y lo considera como parte de un instinto gregario, viviendo en manada (embrión de la sociedad) con otros hombres. Al preguntarse qué es lo que hace al hombre diferente de otros animales, él dice:

En el hombre la materia está conducida por el espíritu; él pudo pues modificar los efectos de la Naturaleza; encontró la manera de resistir a las intemperies de los climas; creó el calor cuando el frío lo destruyó: el des-

1 Por ejemplo, distinguir entre lo universal y lo común, lo universal y uniforme, como lo hace François Jullien (2008). 
cubrimiento y el uso del elemento del fuego, debido a su sola inteligencia, lo hizo más fuerte y más robusto que cualquiera de los animales (Buffon 1984: 271).

A despecho de tales diferencias, el mismo fundamento se mantiene y sobrepasa esas ponderaciones. El humanismo de las Luces se funda en esta categoría trascendente y abstracta del hombre, por eso los filósofos se interesan tanto por el paso del estado de naturaleza al de sociedad. Es preciso comprender este momento inaugural, la chispa que lo separa definitivamente de la animalidad, cuando su universalidad se expresa de manera incuestionable. A despecho de las diferencias históricas, culturales y sociales, se subraya el rasgo unificador. La obsesión por el estado de la naturaleza nada tiene de fortuita (son innumerables los debates al respecto así como fantasiosos sus argumentos) ella materializa un elemento decisivo para el pensamiento: la unicidad del sustrato humano. Una vez postulado ese principio, se puede construir un saber que lo considere como objeto específico. El período de las Luces ve el surgimiento de una ciencia de la moral que se pretende objetiva como los estudios sobre el universo físico y biológico: el saber se emancipa de la trascendencia divina y prescinde de las interpretaciones religiosas para la comprensión del mundo. Ciertamente, hay una diferencia entre los fenómenos de la naturaleza que Turgot consideraba "sujetos a las leyes constantes y encerradas en un círculo donde la revolución es siempre la misma" (Turgot 1997) y la vida social que escapa al ritmo de su repetición. Sin embargo, igualmente en los dos dominios se aplica la noción de ley. Cabría al pensamiento deslindar la lógica de las constantes que rigen la relación entre los hombres. Este es el objetivo de Montesquieu al comprender las leyes que nos gobiernan como "una relación necesaria que deriva de la naturaleza de las cosas" (Montesquieu 1979). Observar la naturaleza humana significa comprender las reglas de conducta así como las instituciones que modelan la convivencia en sociedad: familia, Estado, gobiernos. Ejercicio que desborda el dominio de la mera reflexión, pues los pensadores de la Ilustración están invadidos por un profundo sentimiento de optimismo: descubrir las leyes de la naturaleza y movilizarlas para hacer al hombre feliz.

No se debe imaginar que los iluministas tenían poco interés por la diversidad de las culturas y de los pueblos. Por el contrario, como demuestra Michel Duchet, ellos eran ávidos lectores de relatos de viajes (Duchet 1971). Con el descubrimiento de América y los esfuerzos de circunnavegación del planeta, hacia el año 1770 prácticamente todas las costas del litoral de las tierras habitadas eran conocidas. Los exploradores recorrían esos parajes distantes y condensaban sus aventuras y conquistas en libros que disfrutaban de un gran prestigio entre la elite intelectualizada. El trabajo de 
Duchet es sugestivo porque analiza no solo el contenido de los textos, sino las fuentes que permitieron a los filósofos pensar en determinados asuntos. Voltaire, por ejemplo, poseía una rica biblioteca compuesta por libros que versaban sobre las Tierras Australes, las Indias Orientales, la China, el África, etcétera; la reflexión se ampara de esta forma en un material empírico que le permite trabajar (muchas veces distorsionar) sobre los hotentotes, los indios guaraníes cristianizados por los jesuitas, los papúas, los habitantes de las islas de Tahití.

También Buffon, cuyo interés central es la historia de la naturaleza, dedica un capítulo de sus reflexiones a "la diversidad de la especie humana". Sin embargo, como sostiene Todorov: el interés por lo diverso encuentra una limitación, es válido a partir de que se retorne a la idea de la universalidad del hombre (Todorov 1989).

La universalidad representa su unidad, a pesar de las diferentes razas, costumbres, creencias religiosas; el caleidoscopio de pueblos comparte las virtudes de un único género (iluminado por los filósofos). Ella garantizaría también al pensamiento una veracidad empírica como resultado de la observación y no de la simple divagación metafísica. El objeto hombre se torna entonces pasible de comprensión universal, propiciando las generalizaciones sobre un conjunto históricamente diverso pero filosóficamente homogéneo: la humanidad.

\section{Fundamentos de la naturaleza humana}

Pero la razón no es simplemente un instrumento de conocimiento: es un valor trascendental en el cual se funda la propia naturaleza humana. Cuando Rousseau busca las leyes naturales que rigen la conducta de los individuos, él reflexiona:

[...] en tanto que nosotros no conozcamos al hombre natural, es en vano que queramos determinar la ley que ha recibido o la que conviene mejor a su constitución. Todo lo que podemos ver muy claramente respecto a esa ley, es que no solamente porque es ley es preciso que la voluntad de aquel que ella obliga pueda someterse a ella con conocimiento, sino porque es natural y habla por la voz de la naturaleza (Rousseau 1996: 72).

El raciocinio es circular: la existencia de las leyes naturales ancla en la universalidad de la razón que permite al hombre escoger lo que ellas determinan a su rebeldía. Por eso importa subrayar la dimensión de la elección, pues ella expresa un carácter modal del pensamiento iluminista. El tema de la razón y de la libertad se encuentra en los escritos de los más diversos autores. Por ejemplo, en Hobbes cuando se trata de legitimar la autoridad del soberano. La fábula del contrato social se fundamenta en la idea de un hombre libre, capaz de evaluar racionalmente su situación de penuria y calcular las ventajas de un pacto en el cual todos encontrarían la paz y la felicidad. La 
razón lo conduciría a elegir el bien común, superior a la voluntad individual desreglada. O también en Kant, en el texto "¿Qué es el Iluminismo?". Su respuesta a la pregunta es esclarecedora: "es la salida del hombre fuera del estado de tutela haciéndose él mismo responsable" (Kant 1991: 41).

Se postula la existencia de un hombre guiado por la razón (él es capaz de salir del estado de la tutela) y un conjunto de valores a través de los cuales él actúa en el mundo: espíritu de libertad, uso público de la razón, responsabilidad. La "naturaleza humana" se asocia así a valores políticos y morales cuya realización sería filosóficamente necesaria.

Otro sentido del término se expresa en el contraste que se hace entre sociedad y naturaleza, hombre y mundo animal. Un ejemplo: la distinción establecida por los lingüistas entre lengua y lenguaje. Como observa Saussure, esta última es una facultad universal, una capacidad inherente a la condición humana, mientras que la lengua sería "[...] el conjunto de formas concordantes que este fenómeno asume en una colectividad de individuos y en una época determinada" (Saussure 2004: 115). Para existir, la estructura del lenguaje debe materializarse en un idioma particular. La lengua pertenece al dominio de la cultura y de la historia. Émile Benveniste tiene razón al decir que la idea de lenguaje se aplica solo en sentido figurado al reino animal. Eso no significa que no exista la comunicación entre gorilas, abejas o chimpancés, pero es preciso no confundir lenguaje con código de señales. “El carácter del lenguaje es el de propiciar un sustituto de la experiencia que sea adecuado para ser transmitido sin fin en el tiempo y en el espacio, lo que es típico del simbolismo [humano]" (Benveniste 1995: 65). Se discute entre los estudiosos si su adquisición sería un fenómeno que hubiera ocurrido por etapas o abruptamente; todo lleva a creer que los ancestros de los humanos conocían una especie de proto-lenguaje (la evolución sería gradual). Hay, sin embargo, consenso en decir que solamente un determinado tipo de homínido la posee en su plenitud: capacidad de análisis, interpretación, estructuración de la realidad y función argumentativa (la elaboración del discurso) (Jucquois 2006). Por eso todos los sapiens, para ser más precisos, algunos dicen los sapiens sapiens comparten esta cualidad. Lo mismo se puede decir respecto a la evolución del tamaño del cráneo y del patrimonio genético: los arqueólogos, paleontólogos y genetistas buscan los rasgos universales de los seres humanos. El panorama que ellos retratan, aunque incompleto, debido a las dificultades inherentes a ese tipo de investigación, describe una clara secuencia evolutiva (Coppens 2008, Chaline 2000, Reichholf 1991). Los monos bípedos australopitecos que surgen hace alrededor de cinco millones de años, mezclan algunas de las características de 
los futuros homínidos (caminan en posición erecta), con otras específicas de su especie (tienen los brazos largos). El género homo es más reciente, data de unos dos millones de años. En él se puede observar una caja craneana más desarrollada y transformaciones anatómicas importantes como el surgimiento de la cara y de la quijada. Hay varios tipos dentro de esta especie: habilis, erectus, rudolfensis, etcétera, pero ellos se extinguieron, dando lugar al homo sapiens (hace $180 \mathrm{mil}$ años). Surge en el África y, como las especies anteriores, se esparce por todo el planeta. Los paleontólogos describen este proceso migratorio que dura miles de años. A partir de ese momento la evolución biológica se hace débil o inexistente, al paso que las transformaciones culturales comienzan a acelerarse.

Yves Coppens observa que:

[...] la cultura estuvo desde el comienzo y durante largo tiempo atrasada con respecto a la naturaleza y luego se produjo lo contrario; este punto de inversión, que llamaré el sello cultural de inversión o reverse point, debe ubicarse hace unos 100,000 años. Es particularmente importante porque sitúa el momento de mayoría incontestable del libre albedrío sobre la reacción instintiva (Coppens 2008: 162).

Los vestigios arqueológicos testimonian que diversas técnicas, como la fabricación de objetos y la utilización del fuego, son bastante anteriores al homo sapiens; lo mismo puede decirse de determinadas prácticas como el entierro de los muertos o el empleo de colorantes para pintarse el cuerpo. Sin embargo, el paleolítico superior (de 40 mil a 10 mil años) inaugura otra etapa de la vida del hombre "moderno" (algunos autores hablan de "revolución paleolítica"). Un conjunto de transformaciones indican nuevas formas de organización de la sociedad (D'errico 2006, Kozlowski y Sacchi 2006). En la esfera tecnológica surge el moldeado de las herramientas en la industria del litio, la utilización de la materia animal en la producción de artefactos y armas de caza. En el dominio de las estrategias de subsistencia y exploración del territorio hay un incremento de la alimentación acuática vegetal, la aparición del equipamiento necesario para tostar granos, diversificación de las estrategias de caza, surgen las primeras formas de almacenamiento de alimentos, la organización de determinadas tareas en función del espacio territorial. Existen también cambios de naturaleza simbólica: surgimiento del arte figurativo (30.000 a.C.), presencia de sepulturas con cierto mobiliario funeral que indican la existencia de rituales complejos; aparición de los instrumentos musicales (flauta). No hay cómo negar la importancia de los descubrimientos arqueológicos y de las investigaciones genéticas; de hecho, ellos permiten trazar un cuadro plausible (sujeto a confirmación) del origen y la evolución de los homínidos. Sin embargo, hay algo de insatisfactorio en todo esto. Dentro de la perspectiva considerada, la noción de cultura tiene sentido solo cuando es contrastada 
con la naturaleza. La epopeya de los humanos se aclara, todos ellos fabrican utensilios, conocen el lenguaje, adornan sus vestimentas y sus sepulturas, organizan la vida social en tareas determinadas, son capaces de representar lo real a través de señales y símbolos pictóricos. Por eso se apartan de sus ancestros y del predominio de lo biológico. Recuérdese, además, que es justamente ese rasgo idiosincrático, la cultura, lo que distancia a unos de otros. Cierto, el lenguaje es una facultad universal de los seres que viven en sociedad, pero las lenguas, en tanto su actualización, los separa y los divide. Ese es el dilema de Babel, acontecimiento que alimentó en muchos pensadores la ilusión de la existencia de un idioma, primitivo, perfecto, anterior a la confusión lingüística relatada por la Biblia. La diversidad de las hablas se superpone al rasgo común que les da soporte. Contrapuesta al reino animal, hay realmente una historia de desarrollo de los homínidos que puede ser aprendida a partir de un conjunto de indicios: aumento de la masa craneana, perfeccionamiento de algunas funciones biológicas, consumo de alimentos tratados por el fuego, etcétera. El homo sapiens se diferencia de otras especies de homo así como de las otras formas de vida existentes en el planeta. No obstante, cuando leemos sobre el paleolítico superior tenemos cierta resistencia a imaginar que esos hombres son también diferentes entre sí, cultivan dioses y espíritus diversos, se insertan en sociedades con estructuras de parentesco específicas, hablan lenguas y poseen tradiciones particulares. Se puede anotar un ejemplo preferido por Levy Strauss. El incesto existe en todas las sociedades humanas, sería algo universal. No hay por qué negar tal afirmación; los estudios antropológicos lo demuestran, no obstante, dice mucho sobre lo que las sociedades no son, y poco sobre cómo ellas viven. Lo universal termina donde comienzan la cultura y la lengua. Ese es el problema.

\section{Perspectiva sociológica de la universalidad de la naturaleza humana}

En la tradición sociológica la noción se inviste de otro significado: el énfasis no recae sobre el hombre sino en la sociedad. Él es un ser social modelado por las circunstancias históricas. La definición durkheimiana del hecho social, a pesar de sus equívocos, es esclarecedora. Ella contempla un conjunto de fenómenos con una característica bastante particular: maneras de actuar, sentir y pensar que serían "exteriores" a los individuos (Durkheim 1973). Por exterior deberíamos entender que ellos poseen una vida propia, independientes de las voluntades individuales de aquellos que los expresan. A estos hechos deberíamos denominarlos sociales. La perspectiva sociológica prescinde de la idea de una esencia trans-histórica a la naturaleza humana. Las sociedades son sui géne- 
ris, distintas entre sí, envuelven a los individuos y los insertan en una red de relaciones sociales. En este sentido, la humanidad no existiría como unidad genérica en la que todos estarían incluidos. Eso queda claro, por ejemplo, en la discusión de las categorías de espacio y tiempo. Kant las considera como a priori universales de la mente humana, los hombres compartirían la misma forma (vacía) para construir la espacialidad y la temporalidad de las cosas. Durkheim toma el camino inverso. Para él las personas no clasifican las cosas de manera espontánea o movidas por algún tipo de necesidad natural. Una clase es un grupo de cosas, sin embargo ellas no se presentan a la observación por sí mismas, es necesario agruparlas para que el todo tenga sentido. ¿Pero a partir de qué criterios opera el pensamiento que establece tal jerarquía? Durkheim trata de demostrar que son sociales:

El espacio no es el medio vago e indeterminado que había imaginado Kant... Para poder disponer espacialmente las cosas, es necesario poder situarlas de manera diferenciada: poner unas a la derecha, otras a la izquierda, aquellas arriba o abajo, al norte o al sur, al este o al oeste, etc.... Es decir que el espacio no sería él mismo si no estuviera dividido y diferenciado. Pero ¿de dónde vienen estas divisiones que les son esenciales? Por sí mismo no hay ni derecha ni izquierda, ni arriba ni abajo, ni norte ni sur, etc. Todas estas distinciones vienen evidentemente de que a las regiones les han sido atribuidos valores afectivos diferentes. Y como todos los hombres de una misma civilización se representan el espacio de la misma manera, es preciso, evidentemente, que estos valor afectivos y las distinciones que dependen de ellos les sean igualmente comunes; lo que implica casi necesariamente que sean de origen social (Durkheim 1968: 15-16).

Se abre así la posibilidad de un nuevo campo de estudios, una sociología del conocimiento que se ocupe de las formas cognitivas. Ellas serían moldeadas por los esquemas sociales del conocimiento, no por su supuesta universalidad; por ejemplo: la noción de espacio en el mundo helénico, en el horóscopo chino o del tiempo de la edad media, entre los habitantes de las islas Trobriand. Dentro de esta perspectiva, el hombre existe siempre en contexto; el objetivo de la sociología sería entenderlo, compararlo con otros contextos, construyendo una interpretación, a partir de una realidad empírica determinada, no de un principio normativo o filosófico. Otro ejemplo: el choque con las corrientes filosóficas de su época. Contrariamente a Comte, Durkheim no creía en el progreso rectilíneo de la humanidad; eso significa que difícilmente podríamos considerar nuestra sociedad (me refiero a los europeos) como moralmente más racional que otras. En verdad, el hecho moral se encuentra vinculado a las condiciones sociales que lo conforman. Se comprende así su afirmación:

Nada nos autoriza a pensar que la moral de los llamados pueblos inferiores 
sea inferior a la nuestra. Yo no veo tampoco cómo se la podría comparar de manera de establecer entre ella y las que le han seguido una suerte de jerarquía. La verdad es que no son comparables. Cada tipo de sociedad tiene su moral propia que está implicada en la estructura de las sociedades correspondientes, que está destinada a hacerlas vivir (Durkheim 1975: 67).

Weber también nos ayuda a comprender la problemática que nos interesa. Él llama religiones universales a un conjunto de creencias: judaísmo, budismo, confucionismo, bramanismo, cristianismo, islamismo, cuya aprehensión del mundo propone una ética en la cual el individuo escogería, con mayor o menor grado de autoconciencia, el camino de su salvación (Weber 1984). Weber contrapone esas religiones a las creencias mágicas, en las cuales el elemento de elección, de individuación estaría contenido en las exigencias de las divinidades locales y las prácticas de las costumbres. Desde el punto de vista sociológico merecen ser subrayadas algunas dimensiones de esta universalidad, más allá de la cuestión ética. Primero, la oposición al particularismo, o sea, a las costumbres, valores y poderes restringidos a los límites de las localidades. Las religiones universales, obras intelectuales, reposan en la escritura y tienen una mayor capacidad de universalización. La escritura es fundamental en este proceso, pues, como observa Jack Goody, contrariamente a la oralidad, es una herramienta que propicia la descontextualización de las normas (Goody 1987). El texto posibilita una liberación de los límites provinciales, logrando un radio de mayor amplitud. Favorece la expansión religiosa, vía conversión, dándole un alcance que supera en mucho el localismo de las creencias particulares. Otro aspecto se refiere a la capacidad de integración de los pueblos dentro de una misma norma de sentido. Las religiones universales se asocian a las civilizaciones y muchas veces se constituyen en un centro irradiador de sentido. Ellas consiguen integrar partes distintas dentro de un mismo cosmos de significados. Es el caso de China en la antigüedad (Weber 1964). Una de sus tradiciones filosóficas nace en el siglo IV antes de Cristo y había sido codificada por los discípulos de Confucio a lo largo de los años. Mencio (371298) organiza sus enseñanzas en una versión política coherente y orgánica cuyo objetivo era ofrecer a las familias (como haría más tarde Maquiavelo) un código para gobernar. No obstante, en esa época el confucionismo era solo una entre otras tantas escuelas de pensamiento. Es recién con la unificación del Estado chino (221 a.C.) que se modifica su destino. En ese momento la fragmentación del poder imperial, expresada en las disputas del "feudalismo" vigente, es superada por una fuerza política que encuentra su justificación en la teoría del gobierno por la beneficencia. El confucionismo, como doctrina de Estado, adquiere 
ahora la capacidad universal de integrar las partes del imperio chino dentro de una misma totalidad simbólica. Weber tiene también un particular interés por las relaciones de poder, eso lo lleva a trabajar los conflictos entre los universos religiosos y a comprender sus vínculos como en el campo de la política. Por ejemplo, la contraposición entre ortodoxia y heterodoxia en el caso de la India (Weber 1967). Él muestra cómo el budismo, religión de mercaderes, se desarrolla en la ciudad, en oposición a las fuerzas agrarias que se legitiman a través del bramanismo. La ciudad surge como espacio de contrapunto al poder real, alimentando en las zonas urbanas un camino religioso heterodoxo. La disputa entre budismo y bramanismo configura por lo tanto un conflicto entre "universales" que buscan maximizar sus influencias en términos políticos y religiosos.

La perspectiva sociológica nos permite afirmar la importancia del contexto histórico. Ella nos enseña que existen varios universales que se contradicen y compiten entre sí (confucionismo versus budismo, budismo versus bramanismo, cristianismo versus islamismo, catolicismo versus protestantismo, etcétera). Ellos no existen en abstracto, deben ser calificados y situados históricamente.

El término diversidad es también polisémico, Wieviorka señala que no pertenece al léxico conceptual de las ciencias sociales, sin embargo, en tanto temática, marca diversas tradi- ciones intelectuales (Wieviorka 2008). La antropología nos enseña que la noción de diversidad se encuentra íntimamente asociada a la idea del otro. Inclinándose ante las sociedades llamadas primitivas, los antropólogos de finales del siglo XIX querían comprender un tipo de organización social radicalmente distinta al universo que conocían. Relaciones de parentesco, creencias mágicas, mitos, se encontraban a tal punto distantes, que algunos autores indagaban sobre la existencia de una "mente primitiva", "mentalidad pre-lógica", cuyo funcionamiento escapaba a los patrones del pensamiento occidental (Tylor 1976). La propia noción de observación participante derivaba de esta condición de extrañamiento. Para realizar el trabajo de campo era necesario acercarse a una realidad enteramente desconocida, hacerla presente a través de la experiencia subjetiva, solamente después se la podría traducir a un lenguaje inteligible para el universo académico. Pero las investigaciones antropológicas descubren luego que los grupos indígenas no son solo diferentes a la sociedad industrial, cada uno de ellos constituye una cultura específica, una identidad propia. Guaraní, nuer, hausa, algonquino son elementos discontinuos, particulares, diversos unos de los otros. Por eso el debate sobre el relativismo cultural atraviesa las discusiones de los antropólogos desde la fundación de su disciplina. A pesar de la existencia de corrientes teóricas de 
cuño universalista, como el estructuralismo, la antropología está marcada por una perspectiva que valora la unidad de cada cultura. Los pueblos dispersos en el planeta constituyen, así, una serie diversificada en la cual cada rasgo posee características intrínsecas e irreductibles. La diversidad cultural se expresa en la presencia de sociedades yuxtapuestas en el espacio. La Historia también tematiza la multiplicidad de los pueblos que se interpenetran y se suceden a lo largo del tiempo: egipcios, sumerios, griegos, romanos, chinos, árabes, persas. Cuadro que se transforma de la Antigüedad a la Edad Media, del Estado ilustrado a las conquistas coloniales. Muchas civilizaciones desaparecen, alimentando la creencia de algunos historiadores de que las sociedades humanas serían análogas a los organismos vivos (la problemática del colapso de las civilizaciones es una constante en los escritos de Toynbee). ¿Pero qué es lo que define la noción de civilización? Braudel (1963) la considera un espacio físico y una totalidad económica y social. Siempre es posible localizar una civilización en un mapa, ella posee un centro y un territorio geográfico en el cual se manifiestan sus costumbres, lengua, dioses, formas de gobierno (ciudad-estado, imperio, monarquía). Encierra también una mentalidad colectiva específica, manera de pensar y sentir el mundo. Los historiadores resaltan la importancia de la idea de continuidad, pues toda civilización debe perpetuarse en el tiempo de lar- ga duración histórica. El mapamundi que ellos diseñan está compuesto por puntos asimétricos, en los cuales cada civilización (china, europea, india, musulmana) interactúa entre sí. El mundo contemporáneo sería heredero de la disposición espacial y temporal de esas unidades distintas.

Por último, la sociología nos muestra que las sociedades modernas están marcadas por la diferenciación. Por eso los autores del siglo XIX se interesan por la división del trabajo, esta es clave para explicar el contraste entre la ciudad y el campo, el comercio y la industria, así como la cooperación entre los individuos que viven en sociedad. Existe, por tanto, un proceso de separación y de especialización que se acentúa a lo largo del tiempo. Recuerdo un pasaje de un texto de Marx:

Cuanto más se retrocede en la historia, más el individuo se presenta en un estado de dependencia, miembro de un conjunto más vasto; este estado comienza por manifestarse de forma totalmente natural en la familia, en la familia ampliada, hasta las dimensiones de la tribu; después, en las diferentes formas de comunidades provenientes de la oposición y de la fusión de las tribus. Recién en el siglo XVIII, en la "sociedad burguesa", las diferentes formas del conjunto social se presentarán al individuo como un simple medio de realizar sus objetivos particulares como una necesidad exterior (Marx 1977: 202).

Subrayo la idea de individuación, ella se asocia a las formas específicas 
de vínculos sociales. Las sociedades modernas se oponen a los otros tipos de organización, familia, tribu, etcétera. La temática de la división del trabajo es una preocupación compartida por diversos pensadores y no se configura como una característica propiamente marxista. Basta recordar la oposición entre solidaridad mecánica y orgánica, establecida por Durkheim. Un desarrollo análogo encontramos en la contraposición que Tönnies hace entre los conceptos de comunidad y sociedad. "La sociedad es un grupo de hombres que viviendo y habitando, como en la comunidad, de una manera pacífica unos al lado de otros, están orgánicamente separados; mientras que en la comunidad permanecen ligados a pesar de toda separación, en la sociedad están separados a pesar de toda ligazón" (Tönnies 1977: 81). Los vínculos "naturales" son más fuertes en las organizaciones como la familia, la vecindad, la comunidad rural, donde existe una homogeneidad de las costumbres y de las normas de conducta. El comportamiento individual es regido por el consenso colectivo. La modernidad rompe este equilibrio, separando a los individuos unos de los otros, desarraigándolos de la tradición. En este sentido, la metrópoli se constituye en la expresión metafórica de su realización. No se debe confundir metrópoli y ciudad. Los agrupamientos urbanos son antiguos, pero ellos poseían en el pasado un rasgo comunitario (Tönnies incluye la ciudad griega en el capítulo sobre la comunidad). La metrópoli es el lugar privilegiado de las relaciones anónimas e impersonales, en contraposición a la cohesión de las pequeñas ciudades. Simmel la considera como el espacio donde "estallan las diferencias" (Simmel 1989). La gran ciudad, con la diversidad de su ritmo de vida social, profesional y económica, ofrece al individuo una multiplicidad de estímulos; ella propicia una vida espiritual más rica distinta de la regularidad de los hábitos que marcan la temporalidad rural. La modernidad acarrea en su seno un fuerte elemento diferenciador.

Esta digresión nos lleva a una conclusión análoga a la anterior. La diversidad, en tanto diferencia, no posee un valor "en sí", una "esencia"; existe en situaciones históricas determinadas y debe, también, ser calificada. En este sentido, no es tanto la oposición en relación con lo universal lo que interesa sino cómo el cambio del contexto incide sobre nuestra comprensión de esos términos.

Eso nos remite a la problemática de la globalización. No tengo la intención de trabajarla en sus diferentes dimensiones (lo hice en otros escritos) (Ortiz 1994). Quiero, sin embargo, subrayar un aspecto relevante para la discusión que nos concierne. No creo en la existencia de una "sociedad global", unidad sociológica homóloga a las sociedades nacionales en la cual el proceso de integración de las partes se haría de manera coherente y ordenada. O sea, una metasociedad que engloba todas las otras. El espacio 
transnacional no es de la misma naturaleza que los espacios nacionales. La metáfora de la sociedad global nos ilusiona en este sentido (por ejemplo, muchos afirman la existencia de un espacio público transnacional como si fuese homólogo al espacio público nacional). Tampoco creo que las sociedades sean sistémicas, afirmar la presencia de un world-system me parece problemático. Prefiero decir que el proceso de globalización define una nueva situación. Una situación es una totalidad en la que las partes que la constituyen son permeadas por un elemento común. En el caso de la globalización esa dimensión penetra y articula las diversas partes de esta totalidad. Colocar la problemática en esos términos nos permite evitar un falso problema: la oposición entre lo homogéneo y lo heterogéneo que lleva a pensar simultáneamente entre lo común y lo diverso. ${ }^{2}$ También debemos resaltar otro aspecto. Desde el punto de vista conceptual, al operar con la idea de situación, consigo evitar un tipo de dicotomía común en el debate actual; me refiero a los pares de oposición: moderno/posmoderno, tradición/modernidad, viejo/nuevo, pasado/presente. Normalmente, cada uno de esos términos es visto como una unidad antitética, como si entre ellos existiese una incongruencia insupera- ble. Creo que esta es una perspectiva equivocada cuya lógica excluyente percibe la historia de forma lineal. La situación de globalización se caracteriza por la emergencia de lo nuevo y por la redefinición de lo "viejo", ambos se encuentran insertos en el mismo contexto, en él, diversas temporalidades se entrecruzan. No es pues necesario oponer tradición a modernidad, local a global; importa saber de qué tipo de tradición estamos hablando (¿la tradición de la modernidad o la de los innumerables grupos indígenas?) y pensar en sus formas de articulación a la modernidad-mundo. De la misma manera, lo local y lo nacional no deben ser considerados como dimensiones en vías de desaparecer, se trata de entender cómo esos niveles son redefinidos. En la situación de globalización coexiste un conjunto diferenciado de unidades sociales: naciones, regiones, tradiciones, civilizaciones. En este sentido, aunque integrado en un mercado global, interconectado por tecnologías de comunicación, el mundo nada tiene de homogéneo.

\section{Lengua universal}

Este es el contexto en el cual se debe problematizar lo universal y la diversidad. Un primer aspecto merece

2 Por eso traté de diferenciar entre globalización económica y tecnológica, y el proceso de mundialización de la cultura. El dominio de lo simbólico contiene un conjunto de diferencias que se insertan en el ámbito de la modernidad-mundo (véase Ortiz 2006a). 
ser subrayado: un cambio del humor de los tiempos. Me gustaría destacar esta reflexión a través de un ejemplo: la búsqueda de una lengua universal (Ortiz 2008). Durante siglos, en el mundo occidental esta aventura dominó la imaginación teórica de diversos autores; de la Edad Media al Iluminismo, de la Revolución Francesa a la construcción de los idiomas artificiales (Eco 2002). Al inicio se creía en la existencia de un idioma hablado en el Paraíso que habría dado origen a todas las otras hablas. Babel rompe este equilibrio, el estado paradisíaco de paz cede lugar a la separación de los pueblos y a la incomprensión generalizada. Como la confusión de las lenguas es consecuencia de la intervención divina, el paso de lo uno a lo diverso es visto como una caída, una decadencia. En los siglos XVI y XVII los pensadores abandonan la idea del mito adánico, pero están convencidos de la posibilidad de inventar una lengua universal, capaz de retratar la realidad tal como es, sin la distorsión que las lenguas vulgares infligirían al pensamiento. Este es el momento en que son construidos diferentes sistemas de lenguajes (Dalgarno, Wilkins, Lodwick, Leibniz). En el XVIII, la idea de lengua filosófica se inspira en los mismos ideales, alimenta el debate entre los filósofos y se expresa en la obra máxima de la época, L'Encyclopédie. A lo largo del XIX emergen decenas de propuestas de lenguas artificiales: volapuque (1879), esperanto (1887), spokil, spelin, mundolengua, neutral, y hasta mediados del siglo XX el interés por la existencia de una interlengua se mantuvo exaltado por un cierto militantismo lingüístico. ${ }^{3}$ Cito un ejemplo. En 1795, año III de la República, el ciudadano Jean Delormel presenta a la Convención Nacional un proyecto de lengua universal. Al justificar tal iniciativa, él escribe:

En este momento de revolución, donde el espíritu se regenera en los franceses y se impulsa con tanta energía, ¿no se puede esperar hacer pública una nueva lengua que facilite los descubrimientos acercando a los sabios de las diferentes naciones y que sea asimismo un término común entre todas las lenguas, de fácil aprendizaje para los hombres menos capaces de instrucción, y que haga pronto de todos los pueblos una gran familia?... las luces acercan y concilian a los hombres de múltiples maneras, y esta lengua, al facilitar las comunicaciones, propagará las luces (Delormel 1795: 48-50).

La metáfora de las luces es ejemplar; la razón comunicativa, a despecho de la ignorancia y el oscurantismo, integraría a los hombres en una misma comunidad. Aprender y divulgar tal idioma sería comulgar los valores universales del Iluminismo.

\footnotetext{
3 Mario Pei publica en 1969 su propuesta de una lengua común para toda la humanidad (Pei 1969).
} 
El cuadro lingüístico cambia radicalmente en siglo XXI. Ahora el optimismo en torno a los valores universalistas del monolingüismo pasa a ser visto con desconfianza. Contrariamente a los ideales de una lengua única, surgen innumerables trabajos sobre los idiomas "en riesgo", "en peligro", "en serio peligro", "moribundos", "amenazados" (Grenoble y Wahaley 1998). La crónica de esta muerte anunciada se refleja en el Atlas de las lenguas del mundo en peligro de desaparecer elaborado por la Unesco, que nos revela la agonía lenta de las hablas de los pequeños grupos dispersos por la faz de la Tierra.

Enfrentando situaciones profundamente adversas, disminución drástica del número de hablantes, pérdida de prestigio, necesidad de adaptarse a la convivencia con los idiomas más fuertes, las lenguas en peligro de desaparecer luchan desesperadamente por la supervivencia. La historia bíblica condenaba la multiplicidad lingüística, la redención residía en la espera mesiánica y en la depuración de la decadencia original. Al hipertrofiarse lo uno, la diversidad inevitablemente se inclinaba hacia la imperfección. El cambio de contexto tiene nuevas implicaciones. Los términos del debate se modifican, caminan en otra dirección:

Toda lengua refleja una cosmovisión y una cultura únicas, y muestra cómo una comunidad lingüística ha resuelto sus problemas de relación con el mundo, ha formulado su pensamiento, filosofía y sistema de conocimiento del universo que la rodea. Cada idioma es el medio por el cual se expresa el patrimonio cultural inmaterial de un pueblo, y aún sigue reflejándolo durante un cierto tiempo después de que el impacto con una cultura diferente, intrusa, poderosa y generalmente metropolitana haya provocado la decadencia y el derrumbe de la cultura implícita en esta. Sin embargo, con la muerte y la extinción de una lengua se pierde para siempre una unidad irremplazable de nuestro conocimiento de la cosmovisión y del pensamiento humanos (Wurm 1996: 1).

Hay una inversión de las expectativas. Lo diverso es sinónimo de riqueza, patrimonio intocable. Cada idioma, en su modalidad, es un universo irreductible a los otros, su muerte sería una pérdida para el conjunto de las visiones de mundo de los diferentes pueblos. Las nociones de confusión e incomprensión, intrínsecas a la polémica anterior, son sustituidas por otras, que aprecian lo diverso y lo plural. La idea del monolingüismo se asocia entonces a la preocupación por la imperfección. Se asiste así a una resemantización del mito de Babel: sus deficiencias anteriores se transmutan en positividad. Pluralidad significa riqueza, y la proliferación de las lenguas se torna una cualidad incuestionable.

\section{Religiones como relatos universales}

Una manera de reaccionar a este cambio de humor es considerar como sospecha toda discusión sobre los "particularismos". Dentro de esta perspec- 
tiva estos son percibidos como una amenaza a lo universal, un desvío identitario. ${ }^{4}$ Otra posibilidad, su antípoda, sería abrazar la idea de "fin" de lo universal, tema explorado por la literatura posmoderna. Lyotard, en su clásico libro O Pos-moderno, decía que los grandes relatos habían perdido toda credibilidad, por ser incapaces de legitimar las formas de interpretación del mundo (Lyotard 1986). Particularmente las propuestas que tenían "a la humanidad como heroína de la libertad" o la ciencia como "formación moral e intelectual de la nación" habrían entrado en colapso. En la sociedad posindustrial quedaría a los pequeños relatos el papel de resignificar las formas de comprensión del mundo. Las diferencias contenidas en ellos tenderían a superponerse a las narrativas totalizadoras. En parte Lyotard tenía razón. Algunos relatos ciertamente pierden fuerza. Este es el caso de las ideologías políticas, ellas cultivaron a lo largo del siglo XX la ilusión de que constituían una fuerza intelectual y social capaz de organizar colectivamente las voluntades individuales. Su integridad simbólica estaría expresada en valores y conseguiría, inclusive, orientar la conducta de las personas (esta era la pretensión del marxismo). Esta creencia en la política como "intelectual-orgánico", para hablar como Gramsci, se rompió. Sin em- bargo, algunos no significa todos. Por el contrario, es posible reconocer en la situación de globalización, en la cual las certezas posmodernas son debilitadas, la emergencia de relatos totalizadores y la re-actualización de antiguas narrativas que parecían superadas. Por ejemplo, las religiones universales (Ortiz 2006b). El surgimiento de la sociedad industrial implica el dislocamiento de la centralidad de la religión como fuerza organizadora de los vínculos sociales. El Estado moderno es impersonal y prescinde de la vitalidad de los universos religiosos. Este rasgo se mantiene en el proceso de globalización: la modernidad-mundo no se fundamenta en principios religiosos. Sin embargo, el sentido de las religiones toma otra configuración. Tradicionalmente la oposición entre religión y Estado significaba que el destino de la nación debería aglutinarse en un espacio secularizado; con la Revolución Industrial, el Estadonación es pensado como el lugar ideal para la realización de lo universal de la modernidad (ciudadanía, democracia, libertad). Sin embargo, en el contexto actual la conjunción entre nación y modernidad se escinde, pues la modernidad-mundo traspasa las fronteras de lo nacional. Si hasta entonces la nación era considerada como espacio privilegiado de los valores universales, ahora es solo una "diferencia", un

4 En el plano filosófico y político el libro de Alain Badiou (2007) tiene la intención de cumplir este papel. 
"local" en el ámbito planetario. Las religiones, por su naturaleza, trascienden a los pueblos y a las naciones. Este rasgo, juzgado antes como restrictivo, se convierte en una ventaja. Debido a su vocación transnacional, ellas pueden actuar de manera más amplia, desprendiéndose del constreñimiento de las fuerzas locales y nacionales. Al definirse como algo para "más allá de las fronteras" disponen de un potencial de acción universal. En la medida que tienen la capacidad de agregar personas en escala ampliada, crean lazos sociales y memoria colectiva. En tanto lenguaje, ideología, concepción del mundo, dispersos, pero extensivos a grandes áreas territoriales, los universos religiosos vinculan los intereses y coordinan las acciones colectivas. Disponiendo ahora de medios de comunicación más eficaces, canales de televisión, DVD, correo electrónico, vídeos, internet, ellas tejen los hilos de una "solidaridad orgánica" de alcance mundial (del discurso papal al fundamentalismo islámico). Pero surgen también nuevas propuestas de vocación universal. El ejemplo más elocuente es la ecología. Consideremos el texto de Edgar Morin y Anne Brigitte Kern, Terre-Patri, especie de manifiesto político para el siglo XXI. Ellos parten de la existencia bioantropológica del género homo y están interesados en revelar "la unidad de la especie, la identidad humana, los universales antropológicos" (Morin y Kern 1993). En este sentido, la idea de humanidad, desvinculada de la tradición ilumi- nista, se transforma en una "entidad planetaria y biosférica". La cuestión es: cómo vincular la diversidad de culturas, pueblos, ideologías, existentes en el interior de una misma unidad, el planeta Tierra. La respuesta, en el seno de un proceso en el cual el Estadonación, como fuerza integradora de los individuos, se debilita, se encuentra en algo que les sea común. Universalidad que se aparta de las cuestiones ideológicas o culturales, pues ellas tienden a separar lo que se quiere juntar. El sustrato ecológico se transforma, así, en vínculo asociativo entre los hombres. Es preciso que todos

[...] reconozcan esta cualidad a la Tierra, ella misma padre y madre de todos los humanos... la asociación planetaria es la exigencia racional mínima para un mundo estrecho e interdependiente. Es necesario también en el seno de esta asociación, tener presente la ciudadanía planetaria (Morin y Kern 1993: 138).

\section{Conclusión: ¿Universal o particular?}

La noción de patria utilizada por los autores es sugestiva, encierra una dimensión peculiar: la presencia de una comunidad de valores y de sentimientos. Una propuesta de alcance planetario debe despertar en todos lo que se encuentra adormecido. Sabemos que toda identidad es una construcción simbólica que se hace en relación con un referente, y hay ciertamente una multiplicidad de ellos: étnicos, nacio- 
nales, de género. Para construir sus centralidades, los relatos universales necesitan un referente mundial; el discurso ecológico posee tal cualidad: es elaborado a partir a una referencia totalizadora. Se articula, así, un discurso capaz de comprender de manera coherente y orgánica los problemas de la actualidad que propicia también en los individuos una ética para la acción en el mundo: la defensa del planeta. En la situación de globalización, los relatos de vocación universalista, lejos de desaparecer, son reactivados, inclusive como elementos de "resistencia", como el movimiento alter-globalista cuyo intento es encontrar los caminos para "otra globalización".

La historicidad de las diferencias exige también que sean calificadas. Un primer aspecto se refiere a su no equivalencia; dicho de otra manera: son diferentes entre sí. Existen tribus indígenas, civilizaciones, países, naciones, clases sociales. Los grupos indígenas nada tienen de semejantes, ellos viven situaciones dispares en función de sus historias particulares. Por ejemplo, en Brasil, tradicionalmente, los antropólogos los clasifican según las formas de contacto con la sociedad nacional (Laraia 1995). Al lado de los grupos aislados, existen aquellos cuya relación es intermitente, interactúan ocasionalmente con los blancos. Otra categoría se refiere a los que poseen un contacto permanente con la sociedad que los rodea, aunque no tengan mayor participación en la vida nacional. Por último, los integrados, que son parte del sistema económico, utilizan tecnología moderna, pero mantienen vivas muchas de sus tradiciones y se identifican como una etnia particular. Por eso, como la población indígena es reducida y minoritaria, la lucha por la defensa de la tierra es crucial, por lo que algunos grupos, para preservar su modo de vida, se resisten a aceptar los ideales de la modernización. El panorama es bastante distinto en otros países de América Latina, principalmente en aquellos en los cuales los segmentos de población indígena son mayoritarios (Bolivia, Perú, Paraguay). Como esos sectores se encuentran subalternamente integrados al marco nacional (la noción de contacto no tiene sentido), las reivindicaciones de orden político son de otra naturaleza. Importa tener una mayor participación en la vida pública. La diversidad de las naciones es también patente, desde los países que conocieron la Revolución Industrial en el siglo XIX, a los que se emanciparon del yugo colonial a mediados del siglo XX. Cada nación posee una historia propia: sus conflictos, sus mitos. La diversidad se manifiesta, también, en la esfera del mercado. Los productos son orientados a capas de consumidores, penetran determinados nichos, promueven estilos de vida idiosincráticos. Lejos de ser homogéneo, como pensaban los teóricos de la comunicación de masas, el mercado es atravesado por una miríada de diferencias. Sin embargo, no debemos pensarlas como una esencia, toda diferencia es producida socialmente y es 
portadora de sentido histórico. El relativismo es una visión que presupone la abstracción de las culturas de sus condiciones reales, se tiene la ilusión de que cada una de ellas está enteramente autocentrada. Ese estatuto, postulado por el raciocinio metodológico, es negado por la historia. Las sociedades son relacionales pero no relativas. Sus fronteras se entrelazan y muchas veces amenazan el territorio vecino. El debate sobre la diversidad no se restringe pues al argumento lógico-filosófico, necesita ser contextualizado.

Decir que la diferencia es producida socialmente nos permite distinguirla de la idea de pluralismo. Traducir el panorama sociológico en términos políticos es engañoso, pues presupone que cada una de esas múltiples unidades posee la misma validez social. En esa perspectiva, la cuestión del poder se desvanece. Desde hace poco tiempo se está desarrollando un tipo de literatura que gira en torno al tránsito de lo homogéneo a lo heterogéneo. Está presente sobre todo en los escritos de los ejecutivos de las transnacionales y de ciertos economistas. La historia es aprendida en términos dicotómicos como si estuviésemos en el umbral de una nueva era, una "tercera ola". ${ }^{5}$ En ese sentido, el pasado habría sido unívoco, en tanto el presente se caracterizaría por la multiplicidad de las diferencias y de las identidades. Aplicada al mercado, se asimila lo ho- mogéneo al fordismo, a la producción en masa; y lo heterogéneo a lo diverso, a la flexibilidad. El mundo actual sería múltiple y plural. Diferenciación y pluralismo se vuelven entonces términos intercambiables $y$, lo más grave, ambos se funden en el concepto de democracia. En esta operación lógica hay mucho de ideológico. Esta se olvida de decir que el pluralismo jerarquizado organiza las diferencias según relaciones de fuerza. El retrato de un mundo multicultural, formado por un conjunto de "voces" distintas, es idealizado y falso. Difícilmente podríamos percibirlo como un caleidoscopio, imagen frecuentemente utilizada en su descripción; instrumento que combina los fragmentos coloridos de manera fortuita, en función del dislocamiento de la mirada del observador.

Las interacciones entre las diversidades nada tienen de arbitrarias. Estas expresan los conflictos manifiestos en las situaciones históricas concretas (países fuertes versus países débiles; transnacionales versus gobiernos nacionales; civilización "occidental" versus mundo islámico; Estado nacional versus grupos indígenas). Como corolario de este argumento se puede decir que las diferencias también esconden relaciones de poder. Así, el racismo afirma la particularidad de las razas, para ordenarlas luego según una escala de valor. Por eso es importante comprender en qué momentos el discurso

5 Pienso en el best-seller de Alvin Toffler, The third wave (1980). 
sobre la diversidad oculta cuestiones como la desigualdad. Sobre todo frente a la incuestionable asimetría entre países, clases sociales y etnias.

Lo universal y lo particular son pares antitéticos. El primero nos remite a la idea de expansión, el segundo a la de contención, de límites. La diferencia se asocia a lo particular, a lo específico, y en un principio contrasta con la totalidad y la amplitud de lo universal. No se trata de considerar tal polarización una incompatibilidad entre "sustancias" distintas, sino que ellas configuran cualidades que se encuentran tensionadas por una relación jerárquica. Por eso los pensadores de las Luces hablaban de la diversidad del género humano. Las especificidades eran comprendidas en el marco de una perspectiva unitaria: el género. Sin embargo, en la situación de globalización, muchas veces ese par antagónico se entrelaza mezclando algunos valores que antes estaban vinculados a una de las polaridades. De esta forma se subvierte la relación entre ellos. La afirmación "la diversidad de los pueblos debe ser preservada" utilizada en diversos documentos que orientan las políticas culturales nada tiene de natural. ${ }^{6}$ Por el contrario, deberíamos sorprendernos frente a ese enunciado, pues trae consigo una carga de sentido enteramente nueva. Decir que las culturas son un "patrimonio de la humanidad" significa considerar la diversidad como un rasgo compartido por todos, deberíamos cultivarlo y respetarlo. La crítica al etnocentrismo, asociada por lo general a la dominación occidental, solo puede ser validada cuando se manifiesta como algo que trasciende a la demarcación de cada cultura, de cada identidad. Es eso lo que nos permite decir: "las culturas minoritarias corren el riesgo de desaparecer, necesitamos preservarlas"; "necesitamos valorar todas las facetas de la memoria colectiva de la humanidad"; "el respeto a todas las culturas es un derecho de reconocimiento a la diferencia". En esta operación semántica hay una redefinición que sería incompatible con marcos anteriores: lo diverso se vuelve un bien común. No deja de ser irónico percibir que la valoración de la política de reconocimiento del Otro encuentra en Hegel un férreo universalista, los elementos para su legitimación (pienso en los escritos de Alex Honneth y Charles Taylor). También en la discusión sobre políticas afirmativas nos encontramos con esta aparente paradoja. Se pueden considerar como antagónicas a las acciones universalistas, republicanas, en principio dirigidas a todos; la crítica conserva la dimensión restrictiva que impide su generalización. No obstante, es visible que la valoración se hace en nombre de un ideal también universalista: democracia, igualdad, ciudadanía. Los negros se

6 Véase la Declaração universal sobre a diversidade cultural (Unesco 2002). 
rebelan contra las barreras sociales porque ellas los discriminan en relación con los blancos; la reivindicación identitaria reposa en la denuncia de la desigualdad y de la condición de subalternidad. Esta se fundamenta en una herencia de la modernidad que lejos de extinguirse legitima el discurso y la acción. Humanidad, democracia, ciudadanía, igualdad se convierten en valores compartidos mundialmente, siendo utilizados inclusive para resignificar las diferencias. La idea de la diversidad como valor universal es un oxímoron. Combina términos de sentidos contradictorios, pero que en determinado contexto refuerzan su expresión. Podríamos considerarlo de manera analítica separando los significados, subrayando los antagonismos subyacentes. Sin embargo, en tanto figura de lenguaje, expresa la coherencia de algo que mutuamente parece ser excluyente. Eso es posible porque el contexto se transformó. El oxímoron de la diversidad es un emblema de la contemporaneidad. Cabe al esfuerzo intelectual develar su expresión y sus ambigüedades.

(Traducción: Ana María Cano Correa y Hernán Valdizán Carrasco)

\section{Bibliografía}

Badiou, Alain (2007). Saint Paul: La fondation de l'universalisme. París: PUF.

Benveniste, Émile (1995). “Comunicação animal e linguagem huma- na". Problemas de linguística geral I. Campinas: Pontes.

BRAudel, Fernand (1963). Le monde actuel: histoire et civilizations. París: Librairie Classique Eugène Bellin.

Buffon (1984). "De l'homme". Histoire Naturelle. París: Gallimard.

Chaline, Jean (2000). Un million de générations. París: Seuil.

Coppens, Yves (2008). L'Histoire de l'homme. París: Odile Jacob.

D'Errico, Francesco (abril-junio del 2006). “L'origine de l'humanité et des cultures modernes: le point de vue de l'archéologie". Diogène 214 (edición especial: "Naissance de la pensée symblique et du langage"). París: PUF.

Delormel, Jean (1975). Projet d'une langue universelle, presenté à la Convention Nationale. París: l'Auteur.

Duchet, Michèle (1971). Antropologie et histoire au siècle des lumières. París: Maspero.

Durkheim, Émile (1975). “Une confrontation entre le bergsonisme et sociologisme: Le progrès de la morale et la dynamique sociale". Textes I. París: Minuit.

_ _ (1973). Les Règles de la méthode sociologique. París: PUF.

—_. (1968). Les formes élémentaires de la vie religieuse. París: PUF.

Eco, Umberto (2002). À procura da língua perfeita. Bauru: Edusc. 
Goody, Jack (1987). A lógica da escrita e a organização da sociedade. Lisboa: Edições 70.

Grenoble, Leonore y Lindsay Wahaley (eds.) (1998). Endangered languages. Cambridge: Cambridge University Press.

Jucquois, Guy (abril-junio del 2006). "Langage et communication chez les homidés". Diogène 214 (edición especial: "Naissance de la pensée symblique et du langage"). París: PUF.

Jullien, François (2008). De l'universel, de l'uniforme, du commun et du dialogue entre les cultures. París: Fayard.

KANT, Immanuel (1991). "Réponse à la question: qu'est-ce que les Lumières?". Vers la paix perpétuelle etc (outros textos). París: Flammarion.

Kozlowski, Janus y Dominique SAcchI (abril-junio del 2006). "À la recherche de l'origine de la modernité". Diogène 214 (edición especial: "Naissance de la pensée symblique et du langage"). París: PUF.

Laraia, Roque (1995). “Nossos contemporâneos indígenas". Aracy Lopes da Silva e Luís Grupioni (org.). A temática indígena na escola. Brasilia: MEC/Unesco.

Levy-BruHL, Lucien (1976). La mentalité primitive. París: Retz.

Lyotard, François (1986). O Pósmoderno. Río de Janeiro: José Olympio.
Marx, Karl (1977). Contribuição à crítica da economia política. São Paulo: Martins Fontes.

Montesquieu (1979). De l'esprit des lois (vol. I). París: Flammarion.

Morin, Edgar y Anne Brigitte Kern (1993). Terre-Patrie. París: Seuil.

Ortiz, Renato (2008). "Do flagelo da diversidade ao pesadelo monolinguista". A diversidade dos sotaques: $O$ inglês e as ciências sociais. São Paulo: Brasiliense.

—. (2006a). "Mundialization/Globalization". Theory Culture and Society. Vol. 23, núms. 2-3 (edición especial: "Problematizing global knowledge").

—. (2006b). "Religião e globalização". Mundialização: Saberes e crenças. São Paulo: Brasiliense.

—. (1994). Mundialização e cultura. São Paulo: Brasiliense.

PeI, Mario (1969). One language for the world. Nueva York: Keep-Worthy.

Reichnolf, Joseph (1991). L'Émergence de l'homme. París: Flammarion.

Rousseau, Jean-Jacques (1996). Discours sur l'origine et les fondements de l'inégalité parmi les hommes. París: Libraire Générale de France.

SAussure, Ferdinand (2004). "Linguagem-língua-fala". Escritos de linguística geral. São Paulo: Cultrix.

Simmel, Georg (1989). "Les grandes villes et la vie de l'esprit". Philosophie de la modernité. París: Payot. 
Todorov, Tzvetan (1989). Nous et les autres: La réflexion française sur la diversité humaine. París: Seuil.

Tofrler, Alvin (1980). The third wave. Nueva York: Bantam Books.

Tönnies, Ferdinand (1977). Communauté et société. París: Retz.

Turgot, Robert Jacques (1997). “Tableau philosophique des progrès successifs de l'esprit humain". Formation $\mathcal{E}$ distribution des richesses. París: Flammarion.

TyLoR, Edward Burnett (1958). Primitive culture. Nueva York: Harper.

UnEsCo (2002). Declaração universal sobre a diversidade cultural. París: Unesco.
Weber, Max (1984). “Sociología de la religión". Economia y sociedad. México, D. F.: Fondo de Cultura Económica.

- (1967). The religion of India. Nueva York: The Free Press.

-. (1964). The religion of China. Nueva York: The Free Press.

Wieviorka, Michel (2008). La diversité: rapport à la ministre de l'enseignement supérieure et de la recherché. París: Robert Laffont.

Wurm, Stephen (1996). Atlas de las lenguas del mundo en peligro de desaparición. París: Unesco. 